\title{
Real-Time Computer Analytical Application in Pressure Transient Analysis of Petroleum Reservoirs
}

\author{
Kanya Khatri ${ }^{1}$, Sadiq A. Shah ${ }^{2}$, Agha F. H. Pathan ${ }^{3}$, Bilal Shams ${ }^{4}$, Ashfaque A. Memon ${ }^{3}$, \\ Faisal Hussain ${ }^{4}$, Kanwal K. Pinjani ${ }^{5}$ \\ ${ }^{1}$ Department of Civil Engineering, Mehran University of E \& T, Khaipur Mir's Campus, Khairpur Mir's, Pakistan \\ ${ }^{2}$ Department of Mechanical Engineering, Mehran University of E \& T, Khaipur Mir's Campus, Khairpur Mir's, Pakistan \\ ${ }^{3}$ Department of Civil Engineering, Mehran University of E \& T, Jamshoro, Pakistan \\ ${ }^{4}$ Department of Petroleum \& Natural Gas Engineering, Mehran University of E \& T, Khairpur Mir's, Pakistan \\ ${ }^{5}$ Water Resources Division, National Engineering Services, Lahore, Pakistan \\ Email: rajaln@yahoo.com,memonbs@gmail.com
}

Received May 4, 2013; revised June 7, 2013; accepted July 6, 2013

Copyright (C) 2013 Kanya Khatri et al. This is an open access article distributed under the Creative Commons Attribution License, which permits unrestricted use, distribution, and reproduction in any medium, provided the original work is properly cited.

\begin{abstract}
Today with certainty, the petroleum industry is fostering sanguinely the fields' development programs for the optimization of reservoir characterization through worth-full appliances of computer analysis techniques. The time element is of prime importance for optimistic petroleum development projects. Therefore, the frontline of "Real-time Analysis" is added into the applications of computer solving techniques for achieving and sketching up the real-time cost effectiveness in analyzing field development programs. It focuses on the phases of real-time well test data acquisition system, real-time secure access to the well test data either on field or in office and real-time data interpretation unit. This interface will yield the productive results for the field of reservoir's pressure transient analysis and wells' systems analysis by following the up-to-date preferred, accurate and effective well test analytical principles with modern real-time computer applications and techniques. It also lays emphasis for the comfort and reliability of data in creating best interpersonal working modes within a reputable and esteemed petroleum development organization.
\end{abstract}

Keywords: Reservoir; Pressure Transient; Real-Time Analysis; Comfort; Computer Applications

\section{Introduction}

In the mid of eighteenth century when the oil wells were discovered accidentally through water well drilling, it was felt that the oil was the cheapest combustion source. Later the inventions of vehicles and aircrafts indicated that the hydrocarbons will be the environment friendly substance to run the transport across the world. As the energy demand increases with the passage of time, the more and deep wells were explored and produced with a concern over the economical feasibility of those projects. This further exploration and production of hydrocarbons make the field of petroleum engineering into existence which primarily focuses on reservoir engineering management as it mainly evaluates the producible reserves and project's recoverable economic revenues. The reservoir engineering management helps petroleum engineer in characterizing the hydrocarbon reservoirs via analyzing various well tests conducted in the reservoir at the bottom-hole of the well $[1,2]$. These tests are termed in the petroleum industry as "reservoir's pressure transient tests" while their analysis is known as "reservoir's pressure transient analysis".

As stated above that pressure transient analysis is performed just to characterize the reservoir like to evaluate the physical properties and potential of a reservoir rock in order to produce the hydrocarbons present in it efficiently with maximum recovery. To characterize the reservoir, the basis of pressure transient analysis depends on the graphical interpretation of gradients pressure derivatives versus producible time. This graphical interpretation is obtained via importing the well tests' results. As a reservoir engineer, to fully characterize the reservoir the analytical equations must also be solved optimistically by considering the graphical interpretation results. While the summary of this sketched scenario is not easy to understand nowadays as manually interpreting these graphs and solving the complex analytical equations are unreachable in obtaining the desired results for even a group of various field technicals of petroleum engineer- 
ing field. This is just because of facing the transient flow into the reservoir as the developments go through into more deep formations while it is of common knowledge that the properties of transient flow remain changeable every time by the reservoir's pressure response with respect to location [1].

\section{Basic Concept}

The remedy for the effective pressure transient analysis can be solved by introducing the modern pressure transient analysis which is based on the application of computer aided solutions. These solutions are resulted by importing the well tests' data in order to obtain the upscaled graphical interpretation of gradients pressure derivatives versus producible time. Furthermore, an interface for solving the complex analytical equations via importing the up-scaled graphical interpretation results is used to characterize the reservoir [2,3].

No doubt that the phase of interpreting the obtained well tests' results is very important in petroleum industry as it finally makes a company to generate good economical revenues annually via producing these calculated reserves but this phase calculation must be time saving and live for even just calculating the current reservoir volume in order to become accurate in companies annual economic revenues calculations. By introducing this live data interpretation unit, the working technician will come across to know the current heterogeneities of a producing formation which will make them in making the time effective and cost optimistic live well producing decisions [3]. To brief further this phase, it is defining that a real-time data interpretation unit is designed to interpret the live well test data and to solve the analytical complexities for characterizing the reservoir. Furthermore, this unit is also tried to connect by an internet hub just to make the technicians (which are off to the well location or to any location where reservoir characterization and management experts and engineers have their offices) aware of reservoir conditions which will make them in making live correct decisions. This interface will yields the benefits of accessing the well test data at any location without any risk concern or data insecurity, taking time efficient and cost optimistic decisions and maintaining effective interpersonal connections of reservoir and wellsite engineers to monitor and brief the live reservoir conditions $[3,4]$.

In supplementary aspect the concept leads to the main challenge observed during conventional transient testing. That challenge is the rapid interpretation, processing and analysis of data, which is the responsibility of technical authorities or production experts; instead of any as such personnel only wire line experts are present during wire line operation as it is their foremost responsibility. Now the challenge initiates here that how to enhance the level of communication between wire line experts and data processing experts. The conventional technique practiced currently at field is time, cost and energy consuming. It is capable of providing skillful communication medium between on well personnel, field personnel and technical team at head office.

The subject matter is solved by a newly emerging technology of real time interaction Figure 1. This technology is purely computer system based as it enclose the application of real-time well test data transmission from wire line tester tool to computer, processing it to assess different parameters, storing the data and meanwhile sending it to other concerned personnel via internet [4].

\section{Wire Line Formation Tester}

The universal formation evaluation workflow modules comprises of reservoir mark out by means of seismic information and well-to-well correlations. Further it also includes reserves' volume evaluator-will assist in determination of fluid presence and its productivity. The obtained wire line logs will initially assist endow with fluid type data and productivity. Wire line testing offers proof, comprehensive fluid properties, precise pressure measurements and production evaluation-it's just a way to hunt maximum productivity. Before production of well, formation testing is final evaluation footstep that assist to design well completion and production facilities.

These wire line equipments are either lowers in well by using sonde that is positioned at certain depth. The other method is to attach the equipment with drill pipe/ tubing conveyed by packer.

This one time conducted service of Wire line Formation Tester (WFT) is useful in different domains as to measure the flowing bottom hole pressure, bottom hole flowing rate, permeability of formation, porous opening in producing zone, near well bore parameters, blockage or fractures in reservoir. These testers have also application in determination of assessing reservoir extent and geometry and in investigation of hydraulic communication between wells characteristics and reservoir heterogeneities [5].

The specific operational wire line tester is dart to compute the static pressures of all three permeable layers. Pressure versus depth plots helps in setting up formation

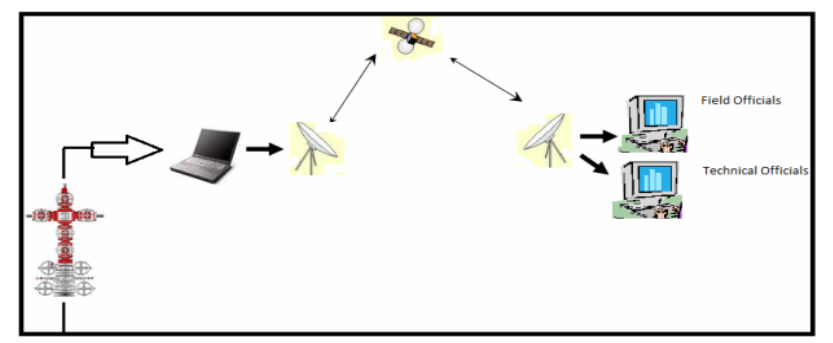

Figure 1. Illustration of real time connectivity system. 
fluid gradients and categorizes fluid contacts in the reservoir. Primary purpose for testing exploration wells is to obtain a fluid sample, so that reservoir fluid must be characterize as it is in a virgin status; in later stages fluid composition may not exactly match the down hole fluid composition due to higher changes [5].

The same test during the development phase discloses different objectives. Most likely the reservoir deliverability is evaluated and the reservoir fluid is distinguished. Then for relating reservoir characterization to the geological model, operator must understand the hydraulic communications $[1,6]$.

At this arena, formation testing principally consists of open-hole wire line pressure testing. It predominantly assists in evaluating static reservoir pressures, which helps in confirming fluid contacts and fluid density gradients. On this mechanism, different hydraulic slots of reservoir will be determined and coupled with geological model. At this stage, additional development wells are drilled and field production already started. In fresh wells, pressure gradients might already replicate manipulation of production on reservoir pressure. If reservoir simulators were in-placed on those wells, it will assist to predict vertical pressure profiles that confirmed by wireline tester measurements. Observed differences (if any) will help in refining geological model and commence suitable slots in the dynamic model. Reservoirs having large number of stacked layers like deltaic deposits, is considered as crucial stage. Therefore here the wireline pressure measurements are very useful aid to reservoir dynamics characterization as it help out in practically assessing vertical and lateral communications and the volumetric structure of these petite entity accumulations. This appliance contributed to the abrupt approval of first wire-line testing tool. Here the key goal of testing development well is to calculate skin that is resultant of formation damage. Due to dearth of skin, we can turn out the wells at their full potential. But ahead of putting the wells on line, the skin must be corrected if highly detected. One more ground for testing development wells is to organize them for stimulations so that it must be produced economically. This is frequent that operator needs premature revenues on many reservoirs having low productivity. These operators usually pay out massive sum on wide-ranging stimulation operations like hydraulic fracturing in the cases when un-stimulated production rates would be uneconomical. Recovering this investment could take months. Like well testing is in particular imperative to evaluate the productivity put on achieved through quantifying skin, estimating fracture length and its hydraulic conductivity, and appraising financial risks $[2,7]$.

\section{Configuration of WFT Module and Data Acquisition}

The WFT string may vary well to well but conventional string comprises of the modules as shown in Table 1.

The data revealed from the subsurface survey was further refined and concluded data is shown in Table 2.

\section{Data Processing}

The input parameters are undergone computation and its given out results are shown in Equation (1).

$$
\frac{(t p+\Delta t)}{\Delta t}
$$

where $t p=72 \mathrm{hr}$.

Permeability, commonly symbolized as $\kappa$ shown in Equation (2), is a measure of the ability of a porous material such as a rock or unconsolidated material, which is the ability to allow fluids to pass through it. It is of importance in determining the flow characteristics of hydrocarbons in oil and gas reservoirs. For a rock to be considered as an exploitable hydrocarbon reservoir without stimulation, its permeability must be greater than

Table 1. WFT tools and their configuration.

\begin{tabular}{|c|c|}
\hline Equipments & Function \\
\hline $\begin{array}{l}\text { Electrical power } \\
\text { module }\end{array}$ & Supply electric power to equipments \\
\hline $\begin{array}{l}\text { 2. Multi sample } \\
\text { module }\end{array}$ & $\begin{array}{l}\text { Collection of high quality fluid } \\
\text { sample for PVT analysis }\end{array}$ \\
\hline $\begin{array}{l}\text { 3. Backup for multi } \\
\text { sample module }\end{array}$ & $\begin{array}{c}\text { Backup module is attached } \\
\text { because limited no. of sample } \\
\text { bottles are attached in single module }\end{array}$ \\
\hline $\begin{array}{l}\text { 4. Hydraulic power } \\
\text { module }\end{array}$ & Powering system of assembly \\
\hline 5. Single probe module & $\begin{array}{l}\text { It contains pressure gauges, fluid } \\
\text { resistivity and temperature } \\
\text { sensors }\end{array}$ \\
\hline $\begin{array}{l}\text { 6. Optical fluid } \\
\text { analyzer }\end{array}$ & $\begin{array}{l}\text { It measure properties of fluid } \\
\text { present in flow line } \\
\text { (either reservoir fluid or drilling fluid) }\end{array}$ \\
\hline 7. Live fluid analyzer & $\begin{array}{l}\text { Quantification of the volume } \\
\text { fraction of C6 components, } \\
\text { essentially liquid HCs and GOR. }\end{array}$ \\
\hline $\begin{array}{l}\text { 8. MRP (Magnetic } \\
\text { resonance Porosity) } \\
\text { Module }\end{array}$ & $\begin{array}{l}\text { Determination of free vs. bound } \\
\text { fluid volume; Detection of } \\
\text { hydrates; Measurement of } \\
\text { mineralogy-independent } \\
\text { porosity; Fluid identification }\end{array}$ \\
\hline 9. Pump out module & $\begin{array}{l}\text { It used to pump unwanted fluid } \\
\text { or mud filtrate from formation } \\
\text { to the bore hole }\end{array}$ \\
\hline $\begin{array}{l}\text { 10. Hold back hydraulic } \\
\text { power module }\end{array}$ & $\begin{array}{l}\text { Backup power system for } \\
\text { additional operations }\end{array}$ \\
\hline $\begin{array}{l}\text { 11. Hold back single } \\
\text { probe module }\end{array}$ & $\begin{array}{l}\text { Hold back modules are used as backup } \\
\text { or for different zone measurement }\end{array}$ \\
\hline $\begin{array}{l}\text { 12. RCI multi tank } \\
\text { carriers/1 Gal sample } \\
\text { module }\end{array}$ & $\begin{array}{l}\text { Application depends on flow } \\
\text { quantity; it is available in } \mathrm{H} 2 \mathrm{~S} \\
\text { and non } \mathrm{H} 2 \mathrm{~S} \text { versions. It contain } \\
\text { throttle valve to control flow. }\end{array}$ \\
\hline
\end{tabular}


Table 2. Subsurface survey revealed data.

\begin{tabular}{|c|c|c|}
\hline Parameter & Source & $\begin{array}{l}\text { Values } \\
\text { received }\end{array}$ \\
\hline $\begin{array}{l}\text { Flowrate }(q) \\
\text { STB/D }\end{array}$ & - Pressure transient test & $500 \mathrm{STB} / \mathrm{D}$ \\
\hline $\begin{array}{l}\text { Total time of } \\
\text { test (tp) hours }\end{array}$ & - Pressure transient test & $72 \mathrm{Hrs}$ \\
\hline Thickness (h) Ft & $\begin{array}{ll}\text { - } & \text { Pressure transient test } \\
\text { - } & \text { Core analysis } \\
\text { - } & \text { Well performance } \\
\text { - } & \text { Seismic survey }\end{array}$ & $22 \mathrm{Ft}$ \\
\hline $\begin{array}{l}\text { Oil formation } \\
\text { volume factor } \\
\text { (Bo) } \mathrm{Rb} / \mathrm{STB}\end{array}$ & $\begin{array}{l}\text { Laboratory analysis of } \\
\text { reservoir fluid samples }\end{array}$ & $1.3 \mathrm{Rb} / \mathrm{STB}$ \\
\hline $\begin{array}{l}\text { Compressibility } \\
\text { (Ct) } \mathrm{psi}^{-1}\end{array}$ & $\begin{array}{l}\text { - } \quad \text { Core analysis } \\
\text { - } \quad \text { Well logs }\end{array}$ & $20 \times 10^{-6} \mathrm{psi}^{-1}$ \\
\hline $\begin{array}{l}\text { Viscosity } \\
(\mu) \mathrm{cP}\end{array}$ & $\begin{array}{l}\text { Laboratory analysis of } \\
\text { reservoir fluid samples }\end{array}$ & $1.0 \mathrm{cP}$ \\
\hline $\begin{array}{l}\text { Radius of well } \\
\text { bore (rw) Ft }\end{array}$ & - Drilling program & $0.3 \mathrm{Ft}$ \\
\hline Porosity (Ø) \% & $\begin{array}{l}\text { - } \quad \text { Core analysis } \\
\text { - Well logs }\end{array}$ & $2 \%$ \\
\hline $\begin{array}{l}\text { Bottom hole pressure } \\
\text { (Pws) psig }\end{array}$ & Pressure transient test & $\begin{array}{l}\text { List mentioned } \\
\text { below }\end{array}$ \\
\hline $\begin{array}{l}\text { Initial pressure of } \\
\text { reservoir }(\mathrm{Pi}) \mathrm{psi}\end{array}$ & - To be computed & Required \\
\hline $\begin{array}{l}\text { Permeability } \\
\text { (k) } \mathrm{mD}\end{array}$ & - To be computed & Required \\
\hline Skin factor (s) & - To be computed & Required \\
\hline $\begin{array}{l}\text { Well bore storage } \\
\text { capacity } \\
\text { (Cs) bbl/psi }\end{array}$ & - To be computed & Required \\
\hline
\end{tabular}

approximately $100 \mathrm{mD}$ (depending on the nature of the hydrocarbon). Because of this reason gas reservoirs with lower permeability are still exploitable because of the lower viscosity of gas with respect to oil.

$$
k=162.6 \frac{q B \mu}{m h}
$$

Well bore storage can be a concern in wells with two characteristics: wells with a near wellbore limit, or wells with long storage times. For wells that have a near wellbore limit, wellbore storage may mask the pressure transient encountering this limit. This could lead to misinterpretation of the pressure transient test and erroneous characterization of the well. For wells with long storage times (greater than 24 hours for example), the length of the shut-in required to derive useful data from a build-up test may not be economically feasible. Well bore storage is denoted by Cs and is given by Equation (3).

$$
\mathrm{Cs}=\frac{q B}{24} \frac{\Delta t}{\Delta p}
$$

And Skin factor is given by equation (4).

$$
s=1.151\left[\frac{P 1 h r-P w f}{m}-\log \left\{\left\{\frac{k}{\varnothing \mu C t r w^{2}}\right\}+3.23\right]\right.
$$

\section{Real Time Analysis}

A software based approach is followed to develop a simulator which not only compute the required parameters on to the spot but also upload the calculated data on internet. This is second phase of the project which enables real time analysis by well site personnel, headquarter and technical experts. This practice not only saves time and cost of analysis but also provides rapid mode of communication. Though all this activity requires permanent training setup but less effort can result in more.

As in previous phase of project the data was feed to software and it developed the transient test model. Now that generated model is then uploaded to internet, meanwhile all other concerned experts can access the data using internet and their assigned ID. This system not only enables these people to check the data but they can also manipulate the parameters to calculate the impact of analysis. Later the manipulation can be accessed by well site personnel too in order to implement the suggested executions.

The data transmission is practiced by satellite system. The Satellite communication system is a line-of-sight microwave system with a single repeater. The satellite is in geostationary orbit as soon as velocity of satellite is harmonized to the rotary motion of earth at the equator. Due to grand expanse of satellite from earth (i.e.; 22,300 miles) and antenna extent margins that frontier focusing capability, the cone of coverage for a single satellite transmitter can be as outsized as the whole South Asia.

Here the transmission service that originates at a solo summit (single point) from well site and stream to number of summits in unit track like technical officials and headquarters, the bulky district of exposure is best. The extensive holdup between instantaneous, a signal is launch and when it returns to earth at filed stations or at other cities (about 240 millisecond) has no detrimental consequence when the signal is going only unit tracked. Real time coordination usually proceeds as a sequence of signals in unit track that are countered or recognized by signals in the other track. When the delay between the signals being sent and the reply or recognition is long, the communication speed of information becomes leisured. For data packets, huge impediment between technical personnel and rig site crew make the structure undergo giant track of accomplishment for transmission $[4,8]$.

\section{Corollary of Real Time Investigation}

1) The pressure transient test was conducted in $72 \mathrm{hrs}$ 
and its data analysis was started exactly the termination of operation. The analysis took negligible time and within hour prior choke size was selected and well was put on production as shown in Figure 2.

2) The parameters were investigated rapidly after test as shown in Tables $\mathbf{3}$ and $\mathbf{4}$ through the output analysis taken from semi-log and log-log determinations given in the Figures $\mathbf{3}$ and $\mathbf{4}$ for well test Table $\mathbf{5}$.

3) Multiple access system results more effective and swift communication as compared to transponder based system because flow of data packets is observed from both ends of communication medium.

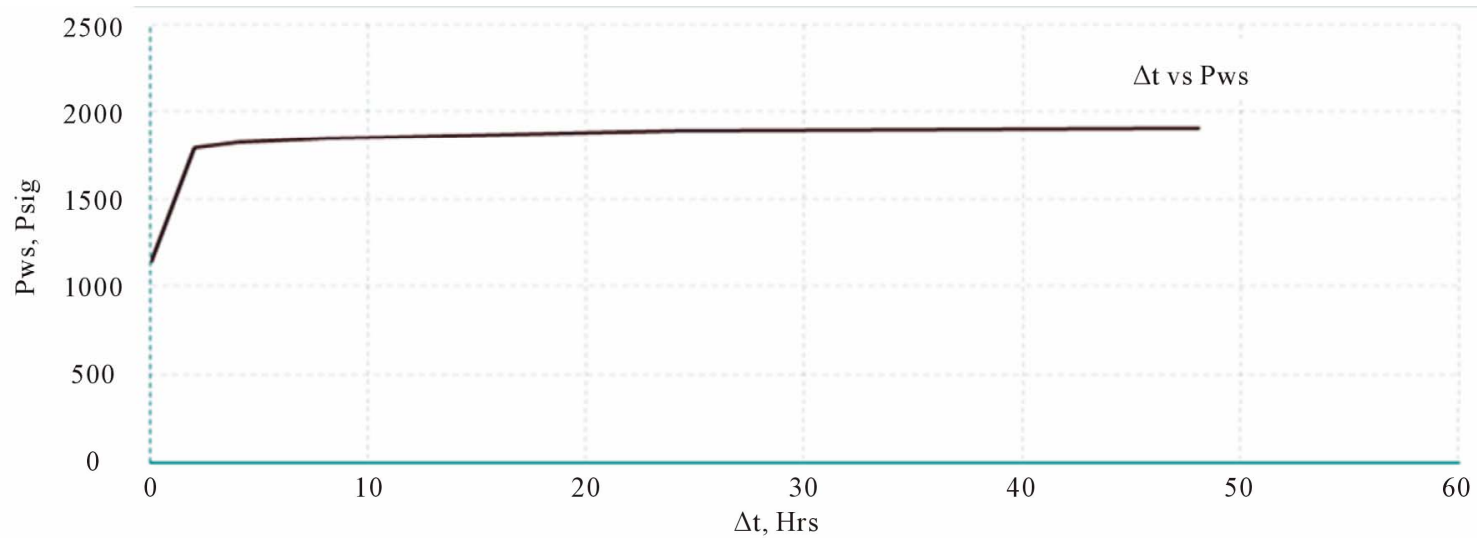

Figure 2. Bottom hole pressure vs time plot.

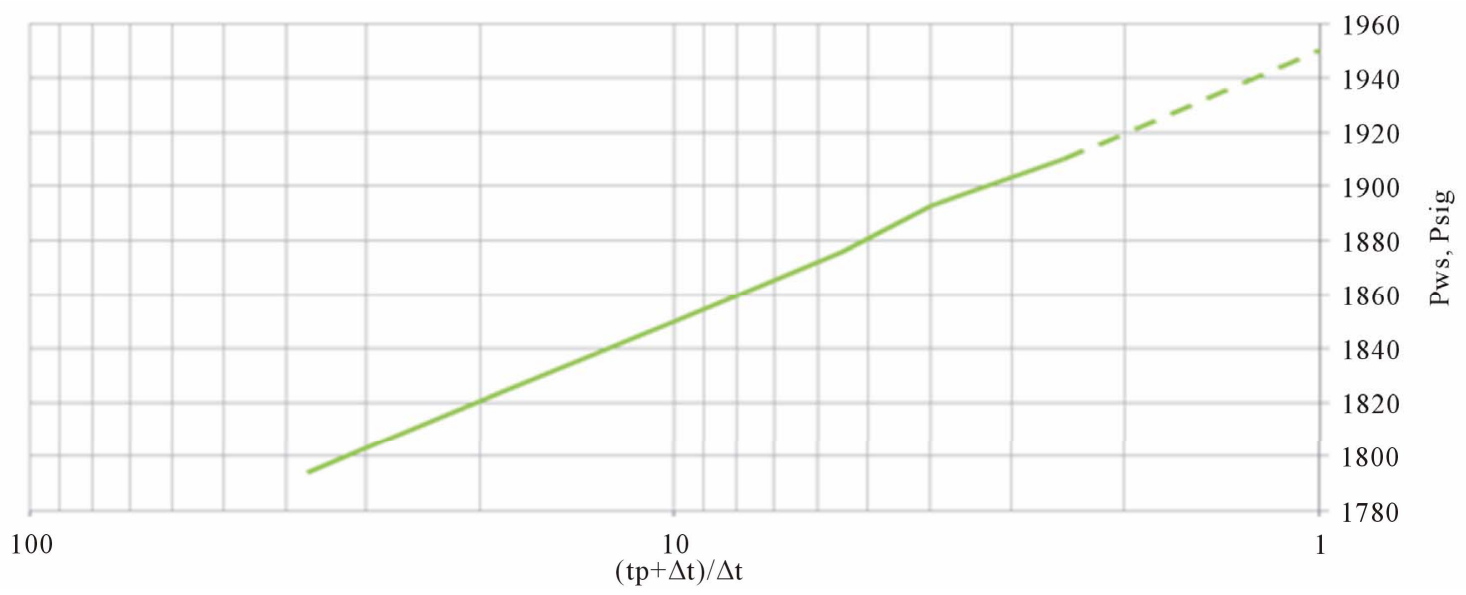

Figure 3. Semi-log plot B/Up (producing layer's initial pressure and slope).

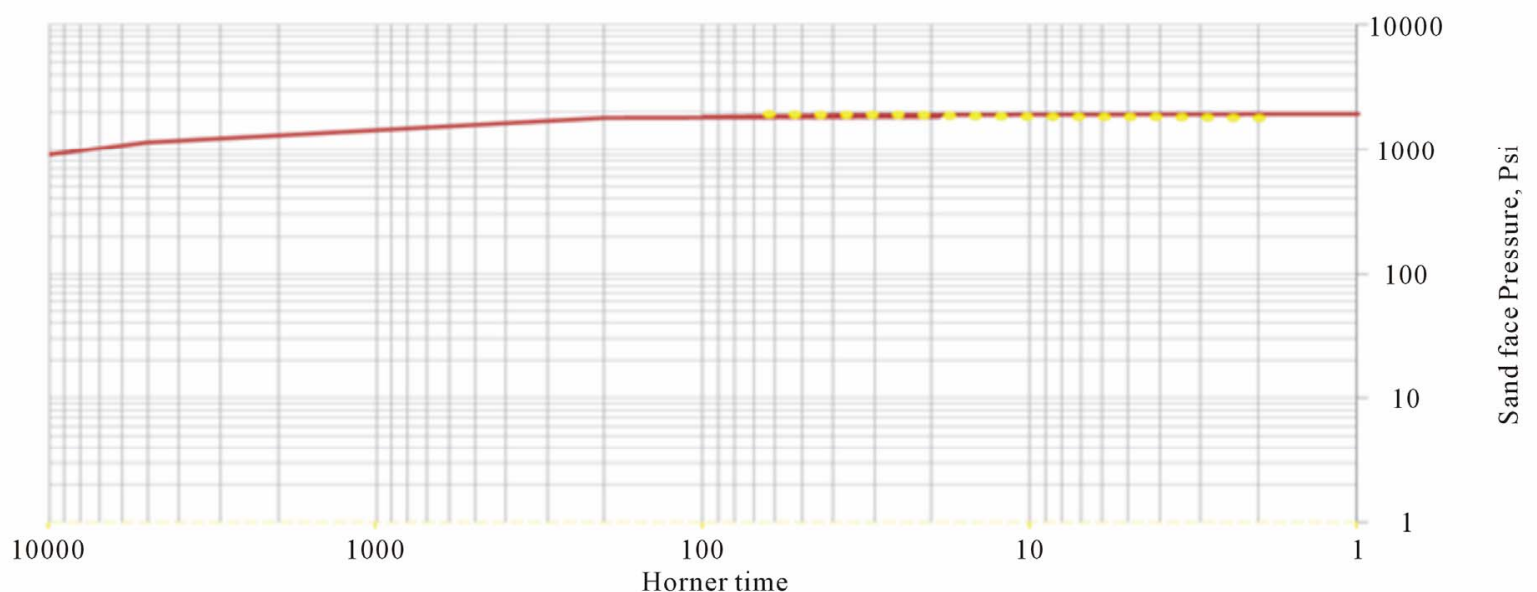

Figure 4. Log-log plot B/Up (producing layer permeability plot). 
Table 3. After test investigated parameters.

\begin{tabular}{cc}
\hline Parameter & Result \\
\hline Slope $(\mathrm{m}) \mathrm{psi} / \mathrm{cycle}$ & $100 \mathrm{psi} / \mathrm{cycle}$ \\
Initial pressure of & $1950 \mathrm{psi}$ \\
reservoir $(\mathrm{Pi}) \mathrm{psi}$ & $48 \mathrm{mD}$ \\
Permeability $(\mathrm{k}) \mathrm{mD}$ & 1.43 \\
Skin factor (s) & $0.68 \mathrm{Bbl} / \mathrm{psi}$ \\
Well bore storage & \\
capacity $(\mathrm{Cs}) \mathrm{bbl} / \mathrm{psi}$ &
\end{tabular}

Table 4. Build up test record from producing layer.

\begin{tabular}{cc}
\hline$\Delta \mathrm{t}$, Hrs & Pws, Psig \\
\hline 0 & 1150 \\
2 & 1794 \\
4 & 1823 \\
8 & 1850 \\
16 & 1876 \\
24 & 1893 \\
48 & 1910 \\
\hline
\end{tabular}

\section{Limitations of Study}

- Suitability of job design remains incompatible to the perforation design and drilling plan. It is required to design the whole operation in series so that equipment size and drilling sections are coordinated.

- Lack of training of well site experts and mobile units result in mismanagement of operation.

- The inter connectivity technology is not implemented routinely on fields so it has very limited applications so far. This technology requires promotion in industry so that petroleum industry can make the most of it.

- Limited access to wireless internet, wireless and mobile connectivity and communication systems on well site can consequently delay the job response. The equipment and devise feasibility are priority in this technology.

- For signals like data communications sessions and real time operations - goes in both directions and anticipated to be received at only one other track, the huge district of exposure and the impediment might root troubles.

\section{Conclusions}

1) WFT dual packer system has proved to be an essential domain for real time analytical application because it enhances the technical scenario of oil and gas fields.

2) The DST, core analysis, well logging and other test data are highly useful in real time planning.

3) Real time analysis provides the means of making onsite and timely decision, which lead to up gradation of technical skills of technical personnel.
Table 5. Lithology of well subjected to test.

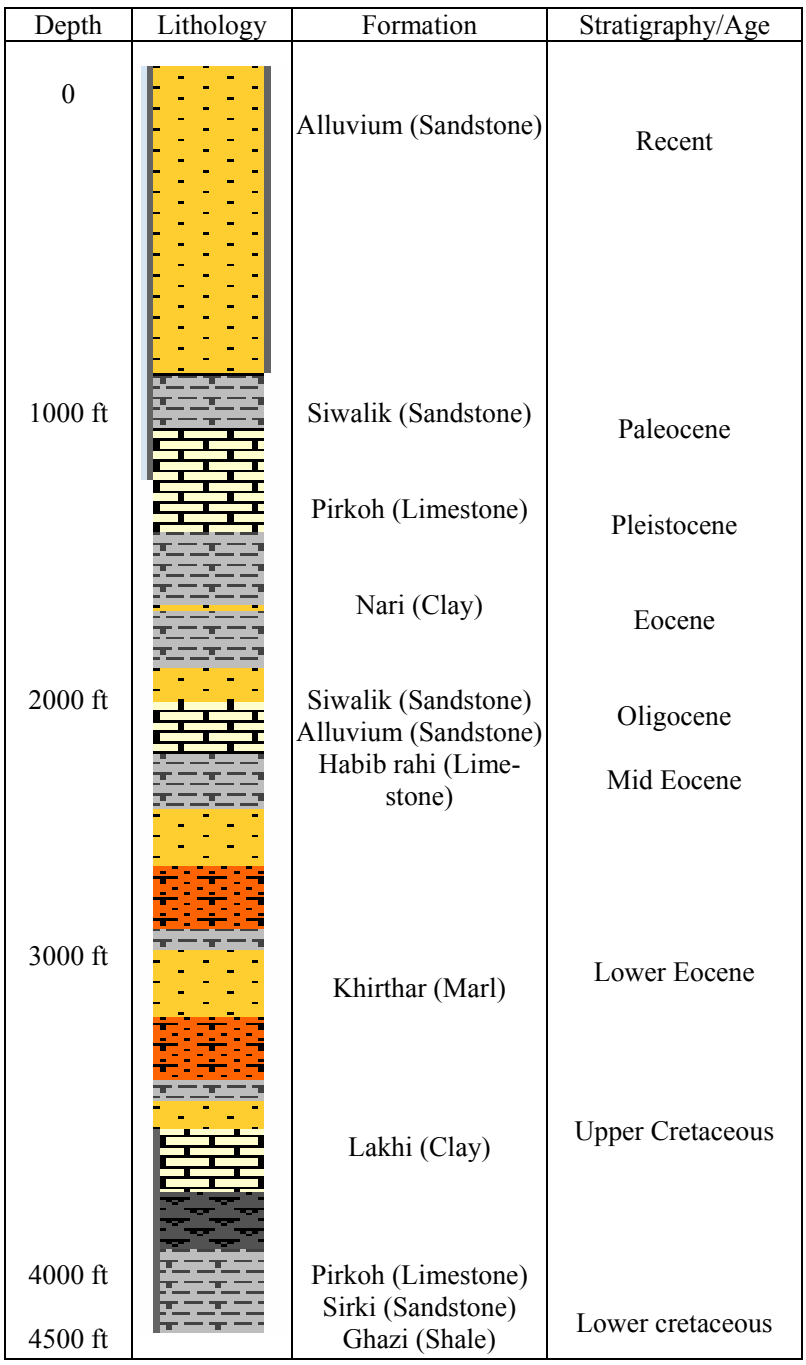

4) Satellite system has proved to be a far better option as compared to fiber optic system, because satellite system facilitates wireless and mobile networking even at well sites.

5) NPNS protocol is important for security purpose. By the application of this protocol, variety of operations can be analyzed at a time (real time) with maximum provision of operation and data security.

6) Real time WFT analysis service is of prime importance for the working environment of Pakistan. Hence it must be promoted and implemented with elevated executions.

\section{REFERENCES}

[1] R. Akkurt, M. Bowcock, J. Davies, C. Del Campo and B. Hill, "Focusing on Down Hole Fluid Sampling and Analysis," Oilfield Review, Vol. 18. No. 4, 2006.

[2] K. C. Kin, L. Chen, C. Ayan-Schlumberger, L. Q. Xu, J. Cai, S. S. Guo, M. W. Wu, Z. T. Hao, F. X. Pan, Z. J. Tan, 
H. J. Yang and CNOOC Zhanjiang Ltd., "Comparing Wireline Formation Tester Derived Productivity Index to Drill Stem Test," SPE Asia Pacific Oil and Gas Conference and Exhibition, Brisbane, 18-20 October 2010, Document ID: 130868-MS.

[3] R. L. Spross, J. A. Truax, P. F. Rodney and D. D. Gleitman, "Downhole X-Ray Source Fluid Identification System and Method," Patent 8511379, 2012.

[4] Schlumberger, "Fundamentals of Formation Testing," 225 Schlumberger Drive, Sugar Land, 2008.

[5] P. Weinheber, "Heavy Oil Sampling with Wireline Formation Testers," International Petroleum Conference, Doha,
7-9 December 2011, IPTC 13917.

[6] Halliburton, "Wireline and Perforating Services," Pressure Transient Analysis (PTA $\left.{ }^{\mathrm{TM}}\right), 2009$.

[7] J. App and C. Ehlig-Economides, "Petroleum Engineering," Pressure Transient Analysis, University of Huston, Huston, 2003.

[8] A. Sageev, "Pressure Transient Analysis of Reservoirs with Linear or Internal Circular Boundaries," SGP-TR-65, Stanford Geothermal Program Interdisciplinary Research in Engineering and Earth Sciences, Stanford University, Stanford, 1993. 